
2019

\title{
Etnomatemática e Trabalho Colaborativo na Educação Inclusiva de Adultos no Contexto da Economia Solidária ${ }^{1}$
}

\section{Ethnomathematics and collaborative work in inclusive adult education and in the context of solidarity economy}

\author{
Renata Cristina Geromel Meneghetti ${ }^{2}$ \\ Edinei de Oliveira Filho ${ }^{3}$
}

\begin{abstract}
Resumo
Este artigo aborda atividades pedagógicas de Educação Matemática desenvolvidas no contexto de um Empreendimento Econômico Solidário (EES). O objetivo desta investigação foi planejar e executar ações pedagógicas neste contexto com base nos princípios da Etnomatemática, a partir de D’Ambrosio, Knijnik, Rosa e Orey e Lübeck e Rodrigues, e também na teoria de Vygotsky referente ao trabalho colaborativo. A investigação seguiu uma abordagem predominantemente qualitativa pautada na metodologia de pesquisaação, a qual buscou promover a transformação social dos membros desse EES pela solução de problemas com relação aos conhecimentos matemáticos envolvidos no cálculo do troco de dinheiro nos processos de venda inerentes às atividades de trabalho dos mesmos. Como resultado observou-se que considerar a Etnomatemática deste EES favoreceu a compreensão e a valorização de práticas matemáticas e que o trabalho colaborativo desenvolvido auxiliou nas discussões sobre procedimentos e conceitos matemáticos, fortalecendo principalmente o princípio da cooperação, que é um dos pilares da Economia Solidária.
\end{abstract}

Palavras-chave: Educação Matemática; Empreendimentos Econômicos Solidários; Educação Especial; Cooperação; Inclusão Social.

\begin{abstract}
This article addresses pedagogical activities of Mathematics Education developed in the context of a Solidary Economic Enterprise (SEE). The aim of this investigation was to plan and execute pedagogical actions in this context based on the principles of Ethnomathematics, starting from D'Ambrosio, Knijnik, Rosa and Orey and Lübeck and Rodrigues; and also, Vygotsky's theory regarding collaborative work. The investigation followed a predominantly qualitative approach based on the action research methodology, which sought to promote the social transformation of the members of this SEE by solving problems with respect to the mathematical knowledge involved in calculating change of money in the sales processes inherent to the activities of their work. As a result, it was observed that considering the Ethnomathematics of this EES favored the understanding and appreciation of mathematical practices and that the collaborative work developed helped in the discussions on mathematical procedures and concepts, mainly strengthening the principle of cooperation, which is one of the pillars of the Solidary Economy.
\end{abstract}

Keywords: Mathematics Educations; Solidary Economic Enterprise; Special Education; Cooperation; Social inclusion.

\section{INTRODUÇÃO}

\footnotetext{
${ }^{1}$ Uma versão anterior deste trabalho foi apresentada no XVIII ENEM. Local: Arena Pantanal, Cuiabá MT. Data: 14 a 17 de julho de 2019

2 Doutora em Educação Matemática. Universidade de São Paulo/USP, São Carlos, São Paulo, Brasil. rcgm@icmc.usp.br

3 Mestrando em Educação para a Ciência. Universidade Estadual Paulista Júlio de Mesquita Filho/UNESP, Bauru, São Paulo, Brasil. oliveira.filho@unesp.br
} 
A pesquisa apresentada neste artigo faz parte de um projeto maior desenvolvido pelo grupo de pesquisa Educação Matemática e Economia Solidária (EduMatEcoSol), do qual fazemos parte, que tem como foco o desenvolvimento de pesquisas e práticas de ensino e aprendizagem de matemática no âmbito da Economia Solidária (ES). Este trabalho é realizado em parceria com o Núcleo Multidisciplinar e Integrado de Estudos, Formação e Intervenção em Economia Solidária/UFSCar (NuMI-EcoSol), o qual tem como propósito promover e dar suporte às atividades de Empreendimentos Econômicos Solidários (EES) na cidade de São Carlos-SP. Esses EES, em seu cotidiano de trabalho, utilizam práticas relacionadas às maneiras de observar, comparar, organizar, classificar, medir, quantificar e contar, que são práticas próprias do saber/fazer matemático.

Para Singer e Souza (2000), a ES visa, primeiramente, proporcionar às pessoas que a adotam uma vida melhor, não apenas no sentido de que possam consumir mais, mas também em relação ao relacionamento com a sociedade e colegas de trabalho. Assim, a ES foi concebida com a finalidade de unir a forma industrial de produção com a organização da vida em sociedade. Ademais, para Kruppa (2005), a ES propõe a igualdade de condições e o direito às diferenças, de maneira que os empreendimentos que participam dela não sejam hierarquizados, que sejam democráticos e não promovam desigualdades.

Entendemos ainda, de acordo com Singer (2002), que a ES deve estar baseada na cooperação entre os que dela participam, na solidariedade, na autogestão do empreendimento, na propriedade coletiva do capital e na liberdade individual; valorizando todos os seus membros de forma igualitária e buscando a inclusão dessas pessoas na sociedade. Em geral, os EES são formados por pessoas que foram excluídas socialmente no sistema capitalista por estarem desempregadas, com uma idade avançada para conseguir novos empregos, por questões de escolaridade ou entre as mais diversas causas das exclusões nesse sistema econômico. No caso dessa pesquisa, os membros do EES participante foram excluídos tanto pela falta de escolaridade quanto pela condição do transtorno mental, ou seja, trata-se de uma condição dupla de exclusão social.

Os transtornos mentais são geralmente caracterizados, segundo a OPAS (Organização Pan-Americana de Saúde), por uma combinação de pensamentos, percepções, emoções e comportamentos que podem afetar as relações com outras pessoas. Entre os 
transtornos mentais estão a depressão, o transtorno afetivo bipolar, a esquizofrenia e outras psicoses, a deficiência intelectual e os transtornos de desenvolvimento. $\mathrm{O}$ acesso aos cuidados de saúde e aos serviços sociais capazes de proporcionar tratamento e apoio social é fundamental para pessoas com transtorno mental (Brasil, 2018).

O EES atendido pelo Grupo EduMatEcoSol no recorte dessa pesquisa possui como ocupação a produção de artesanato a partir do papel reciclado e iniciou suas atividades no ano de 2006. Este empreendimento tem por finalidade a inclusão no mercado de trabalho de adultos que apresentam diagnóstico de algum transtorno mental. Tal EES produz diversos tipos de produtos artesanais, como: porta-canetas, agendas, cadernos, pastas etc. Os trabalhadores são assistidos por um CAPS (Centro de Atenção Psicossocial) que são serviços de saúde de caráter aberto e comunitário que realizam, prioritariamente, atendimento às pessoas com sofrimento ou transtorno mental, incluindo aquelas com necessidades decorrentes do uso de álcool e outras drogas. Centros como este funcionam em todo o território nacional e atuam em situações de crise ou nos processos de reabilitação (Brasil, 2019).

Nossas atuações pedagógicas junto a esse empreendimento consistiram em conhecer e compreender melhor seu cotidiano e funcionamento, atentando-nos para as dificuldades vivenciadas pelo grupo, em especial, aqueles referentes ao conhecimento matemático e, a partir disso, elaboramos atividades didático-pedagógicas de matemática que contextualizassem o cotidiano de trabalho desse grupo e visassem a superação dessas dificuldades. Na primeira fase de atuação foi possível levantar um diagnóstico inicial em que observamos que os cooperados possuíam diferentes níveis de déficit em relação às operações elementares de matemática envolvendo números naturais e racionais, principalmente, na forma decimal no contexto da devolução do troco ao cliente perante a venda de um produto. A partir desse levantamento, estabelecemos algumas estratégias de ações pedagógicas em Educação Matemática focalizando situações-problema sobre números decimais, as quais foram abordadas junto aos membros desse EES em horário combinado com os mesmos, visando à superação dessas dificuldades.

Compreendemos, ainda, que é importante citar que devido aos transtornos mentais, os membros desse EES eram acarretados por Necessidades Educacionais Especiais (NEE), e nesse sentido, a pergunta norteadora deste trabalho é: como a Educação Matemática pode ser abordada no contexto da Educação Inclusiva de Adultos e da Economia 
Solidária visando sanar algumas dificuldades de trabalho de pessoas com Necessidades Educacionais Especiais e contribuir com os princípios deste tipo de economia?

O objetivo desta investigação foi, a partir do cotidiano desse EES, planejar e executar intervenções pedagógicas de Educação Matemática com a finalidade de sanar as dificuldades com relação aos números decimais no contexto das vendas dos artesanatos, com base nos princípios da Etnomatemática D’Ambrosio, (1996, 2001, 2008, 2018), Knijnik (2001), Knijnik e outros. (2012), Rosa e Orey (2018) e Lübeck e Rodrigues (2013) e por meio da realização de um trabalho colaborativo (Vygotsky, 1991). Além disso, visou-se também a inclusão social dos membros deste empreendimento, a busca da emancipação dos seus processos produtivos favorecendo não só a inserção de pessoas com algum transtorno mental no mercado de trabalho e em processos de ensino e aprendizagem, mas também uma forma de geração de renda para elas. Desta forma, entendemos que eles poderão sentir-se autoconfiantes de suas possibilidades e eficazes na sociedade novamente. As intervenções pedagógicas focalizadas neste trabalho se deram, inerentes ao desenvolvimento de um projeto de iniciação científica sob a orientação da primeira autora deste artigo e com a participação do segundo.

\section{FUNDAMENTAÇÃO TEÓRICA}

Sabe-se que atualmente o capitalismo é o sistema econômico predominante no Brasil, baseado na propriedade privada dos meios de produção e acúmulo de capital, o qual acarreta o fortalecimento das desigualdades sociais e a competição, favorecendo àqueles que possuem melhores condições financeiras, pois terão mais recursos para vencer as competições estabelecidas. Essa competição funciona como forma de reprodução da sociedade e colabora na manutenção das desigualdades sociais, visto que aqueles que começam com mais recursos tenderão a continuar vencedores em competições estabelecidas futuramente, visto que já iniciam em uma posição vantajosa, mantendo e/ou aumentando as desigualdades já estabelecidas. Em contrapartida e na direção de uma proposta alternativa temos a ES que valoriza a cooperação entre os participantes ao invés da competição e luta para que a classe excluída pelo sistema capitalista possa ter condições dignas, buscando a igualdade entre os participantes (Singer \& Souza, 2000). Além da cooperação, a ES é pautada em outros três princípios: autogestão, viabilidade econômica e solidariedade. Entende-se a cooperação como existência de interesses e 
objetivos comuns, propriedade coletiva dos bens, partilha dos resultados e responsabilidade de todos os participantes. A autogestão engloba a participação de todos os membros no processo de trabalho e nas decisões cotidianas dos empreendimentos. A viabilidade econômica é a agregação de esforços para viabilizar a produção, prestação de serviços, comercialização e consumo. E a solidariedade é uma preocupação permanente para a justa distribuição dos resultados e a melhoria das condições de vida de participantes (Brasil, 2006). Ademais, um EES pauta-se nos princípios da ES e tem como diferença de uma empresa comum ao sistema capitalista, principalmente, a sua forma de administração. Enquanto na primeira ocorre a "heterogestão", isto é, a administração obedece a uma hierarquia com as ordens fluindo de cima para baixo, em um EES temos a "autogestão", ou seja, as decisões são tomadas de forma democrática, em assembleias constituídas por membros dos empreendimentos (Singer e Souza, 2000). Ademais, alguns aspectos podem ser colocados como importantes para um bom funcionamento de um EES, como a superação de conflitos entre os trabalhadores, a busca do mesmo objetivo e tomadas de decisões coletivas, nas quais os votos de cada cidadão têm a mesma validade. Além disso, os sócios de um EES decidem coletivamente como os ganhos devem ser partilhados entre os participantes (Meneghetti \& Cunha, 2016).

Como o capitalismo é pautado na competição e na obtenção de lucros, isto é, na diminuição das despesas e aumento dos ganhos, fica claro que é necessário para essa economia um suporte advindo da matemática, pois por meio dela são feitos os cálculos importantes para projeções desses lucros. Já na ES, que é baseada na cooperação e na autogestão, é necessário que a matemática seja utilizada nas atividades de cálculos dos valores excedentes e das práticas em comercialização, considerando os princípios desta economia de um grupo específico. Nesse sentido, Meneghetti (2013) salienta que é possível uma aproximação da Educação Matemática com a ES por meio da Etnomatemática, pois esta visa entender a realidade dentro de um contexto cultural próprio, isto é, compreender os saberes matemáticos utilizados nas tarefas cotidianas de um EES.

A Etnomatemática surgiu na década de 1980 como uma área de pesquisa em História e Filosofia da Matemática e suas implicações pedagógicas. A sua ideia central consiste no reconhecimento de que diferentes culturas têm diferentes maneiras de lidar com 
situações relacionadas a seu contexto natural ou social. Assim, a Etnomatemática pode ser considerada um programa de pesquisa que foi expandido durante os anos, a fim de compreender melhor o sistema complexo de comportamento e conhecimento gerado e organizado por cada indivíduo inserido em uma cultura específica (D’Ambrosio, 2018). A etimologia da palavra Etnomatemática, ainda segundo D’Ambrosio (1996), tem raízes gregas: techné (tica), que significa as maneiras e/ou técnicas; matema, que está relacionado aos saberes e fazeres, isto é, as explicações e entendimentos das situações e dos problemas de um etno, que significa um meio social/ cultural próprio. Ou seja, são as maneiras ou técnicas de saber e fazer próprias de uma cultura ou sociedade.

A Matemática Acadêmica, que é feita nas pesquisas dentro das universidades, foi originada nas culturas da bacia do Mediterrâneo, da Mesopotâmia (Iraque antigo) e das civilizações do vale do Nilo, adquirindo, posteriormente, um modo de saber e fazer próprio que foi baseado em um forte rigor nas demonstrações advindas da cultura da Grécia antiga, mais precisamente da obra de Euclides e, portanto, pode ser considerada uma Etnomatemática. Nesse sentido, o Programa Etnomatemática tem como intuito uma ampla investigação da evolução das ideias, das práticas e do conhecimento da espécie humana em diferentes ambientes culturais, isto é, como utilizam práticas relacionadas às maneiras de observar, comparar, organizar, classificar, medir, quantificar e contar, que são práticas próprias do saber/fazer matemático (D’Ambrosio, 2018).

Desde o surgimento a Etnomatemática evidencia uma preocupação em considerar relevante as diferenças culturais no âmbito da Educação Matemática, principalmente com relação ao saber/fazer matemático, de um contexto de pobreza, desigualdade social e exploração econômica. Nesse sentido, por meio da Etnomatemática, busca-se desmistificar a existência de uma forma única de produção de matemática, destacando outras formas, principalmente as advindas das culturas não dominantes (Knijnik et al., 2012).

Com isso, nosso trabalho buscou a compreensão de quais são os conhecimentos próprios do saber/fazer matemático do EES investigado, isto é, a Etnomatemática desse EES (composto por pessoas que não pertencem a um grupo cultural dominante), e por meio de intervenções pedagógicas, visando contribuir para a emancipação dos processos de venda desse empreendimento. 
“A relação entre Educação Matemática e etnomatemática se dá naturalmente, pois etnomatemática é uma forma de se preparar jovens e adultos para um sentido de cidadania crítica, para viver em sociedade e ao mesmo tempo desenvolver sua criatividade" (D’Ambrosio, 2008). Considerar um ensino por meio da Etnomatemática, portanto, não implica em enxergá-la como uma disciplina do ensino tradicional, assim como é a matemática, mas sim como uma pedagogia diferente, que não incorra na utilização, repetição e reprodução pelo aluno/aprendiz de um conhecimento que está no livro didático, mas como algo vivo e dinâmico, que seja uma resposta aos seus problemas sociais/culturais cotidianos. Assim, torna-se importante propor situações em que o aprendiz resolva e explique situações gerais do seu ambiente cultural a partir das suas experiências prévias (D’Ambrosio, 2008).

Para tal, Rosa e Orey (2018) tratam do Currículo Trivium que pode auxiliar que os estudantes/aprendizes desenvolvam, através de um processo de ensino e aprendizagem de matemática, as capacidades da Literacia, Materacia e Tecnoracia. A Literacia é a capacidade de processar informações próprias do cotidiano, tais como: verificação de preços, interpretação de gráficos e tabelas, utilização de unidades de medida, realização de operações matemáticas, entre outros. A Materacia é a capacidade de interpretar códigos e analisar os fenômenos cotidianos. Propõe-se que isso seja feito por meio da elaboração de modelos com a utilização dos procedimentos e conteúdos que estão dentro e fora do ambiente escolar. E, por fim, a Tecnoracia é a capacidade de combinar ferramentas tecnológicas de maneira crítica. Os autores também apresentam a Numeracia, entendida como a capacidade da utilização do conhecimento matemático de forma a facilitar o cotidiano, em que se exige a aplicação do senso numérico, das operações matemáticas e do tratamento da informação (Rosa \& Orey, 2018). No decorrer da pesquisa foi possível identificar que, ao resolver e explicar problemas próprios do ambiente cultural, o Currículo Trivium se fez presente para o EES em questão por meio da Literacia, e a Numeracia foram utilizados e aprimorados durante as intervenções pedagógicas.

Como apontado anteriormente, esse EES é formado por pessoas duplamente excluídas do mercado de trabalho: essas têm, em sua maioria, baixa escolaridade e, além disso, possuem algum transtorno mental. Com as reformas psiquiátricas e a extinção dos manicômios, sujeitos em sofrimento psíquico foram inseridos na sociedade. Com isso, a 
necessidade de troca de mercadoria e de trabalho apareceu em suas vidas. Nesse contexto, Pinho e Machado (2015) observaram em atividades autogeridas e coletivas fontes importantes para que isso ocorresse. Dessa forma, a ES vem viabilizando conquistas e avanços nesse caminho, já que existe uma procura pela geração de trabalho e renda e pela inclusão social.

A inclusão, nesse sentido, pode ser entendida, de acordo com Lübeck e Rodrigues (2013), como meio de garantir o direito das diferenças de que não exista estigmas, segregações e marginalizações (advindas das diferenças sociais, culturais, históricas, psíquicas, biológicas, físicas, entre outras). Para esses autores, uma forma da Educação Matemática ser inclusiva é por meio da Etnomatemática, uma vez que essa valoriza a solidariedade, o diálogo e a cooperação entre as pessoas, o reconhecimento dos diferentes saberes e fazeres. E ainda, porque a Etnomatemática não se pauta no eurocentrismo, não valoriza apenas os grupos que são dominantes, mas os que são diferentes, os que podem ser excluídos da sociedade; ou seja, ela torna-se inclusiva a partir dos respeitos das diferenças.

Os membros do EES participante desta investigação estão em um grupo que foi excluído da economia capitalista por conta dos transtornos mentais, da falta de escolaridade e do desemprego e, nesse contexto, eles buscaram na formação de um EES a inclusão na sociedade. Mas, constatamos dificuldades no que se refere à utilização de conhecimentos matemáticos necessários nas atividades de produção e comercialização do grupo. Na perspectiva de Lübeck e Rodrigues (2013), de uma Educação Inclusiva, uma forma possível de superação dessas dificuldades tem sido o emprego de ações educativas de matemática considerando os pressupostos teóricos da Etnomatemática. Intervenções anteriores realizadas neste cenário foram abordadas em Meneghetti e Gargarella (2019), por meio das quais constatou-se que, devido ao fato dos membros do EES possuírem transtornos mentais, as principais dificuldades do grupo estavam relacionadas a conteúdos básicos de matemática, tais como soma e subtração no conjunto dos Naturais. Em intervenções pedagógicas realizadas por meio de situaçõesproblema contextualizadas se fez o uso de materiais concretos, como o ábaco para representação do sistema posicional (unidade, dezena, centena e milhar), notas fictícias para representação do sistema monetário brasileiro e canudos de plástico com a finalidade de corresponder um canudo a uma unidade monetária para facilitar o 
procedimento de soma. Nesse contexto, ao utilizarem-se dos materiais concretos, as autoras perceberam que os membros desse EES tiveram uma melhor compreensão relacionada ao nosso sistema monetário e conceitos matemáticos necessários em suas atividades de trabalho, contribuindo com o princípio da autogestão possibilitando ao grupo pesquisado um maior domínio dos seus processos produtivos e das suas relações de venda.

A partir do trabalho supracitado, que apresenta o modo como os membros do EES sanaram suas dificuldades relacionadas a alguns conteúdos básicos de matemática, novas observações participantes foram feitas e, com isso, constatou-se a possibilidade de trabalhar com esses conteúdos relacionados ao processo de compra e venda na feira, local onde a mercadoria produzida é comercializada. Isto porque os próprios cooperados relataram ainda ter insegurança no processo do cálculo do troco, além de existir uma grande rotatividade nesse EES, em que muitos dos participantes das vendas eram diferentes dos das intervenções feitas anteriormente. Para tal, foi utilizada uma metodologia de trabalho colaborativo com base em Vygotsky, gerando maior cooperação entre os membros do EES, um dos princípios da ES. Assim, no trabalho anterior de Meneghetti e Gargarella (2019) buscou-se fortalecer o princípio da autogestão, já na pesquisa descrita nesse artigo tivemos como objetivo contribuir, principalmente, com o princípio da cooperação.

Este trabalho se justifica pela importância da Educação em ES que tem, segundo Adams e dos Santos (2013), como um de seus intuitos, considerar os problemas e as necessidades dos EES e educar para o compartilhamento do trabalho. Para tanto, é importante evidenciar que as metodologias de ensino estejam de acordo com os princípios da ES. Ademais, para esses autores, a relevância da Educação em ES está atrelada ao cotidiano de trabalho coletivo e autogestionário, no qual os trabalhadores podem experienciar o trabalho na prática educativa. No nosso caso, a ênfase foi dada à Educação Matemática contextualizada à realidade e às necessidades desse EES.

Nesse sentido, esse artigo aborda como a Educação Matemática pode auxiliar no fortalecimento dos princípios da ES, em especial o princípio da cooperação, com o objetivo da transformação social e reintegração do trabalho de pessoas duplamente excluídas socialmente. Isso pode ser feito através de uma abordagem que leve em conta o respeito, a solidariedade e a cooperação, que além de fazer parte de uma educação 
inclusiva com base na Etnomatemática são pilares da ES. Também, através dos saberes e fazeres matemáticos próprios do cotidiano de trabalho do EES e por meio da realização de um trabalho colaborativo, desenvolvido a partir das teorias de Vygotsky, que podem trazer grandes contribuições com relação ao ensino de pessoas com NEE. De acordo com Costa (2006), para Vygotsky a deficiência não é um limitador para o desenvolvimento da inteligência, o que a limita são as relações sociais mal estabelecidas entre a sociedade e o sujeito com NEE. O indivíduo constitui-se por meio das relações sociais, culturais e da interação com o outro. Assim, o desenvolvimento de indivíduos com NEE carece de forma significativa da interação com os sujeitos com uma bagagem cultural maior, entendemos que isso pode ser feito através de um trabalho que considere a Zona de Desenvolvimento Proximal do indivíduo. Segundo Vygotsky (1991) esse nível proximal caracteriza-se pela distância entre o nível real de desenvolvimento (determinado pela capacidade do indivíduo de resolver tarefas independentemente) e o nível de desenvolvimento potencial (determinado pela capacidade do sujeito de resolver problemas com ajuda de outras pessoas podendo ser, por exemplo, um colega mais competente ou experiente nesta tarefa).

Segundo Damiani (2008), a teoria de trabalho colaborativo, advinda das teorias educativas de Vygotsky, aborda trabalhos conjuntos em grupos e oferecem vantagens ao aprendizado não encontradas na realização de trabalhos individuais, pois considera que a formação do sujeito e do seu pensamento são provenientes da interação social com outros sujeitos. Assim, a interação educando/educando e educando/educador pode ser efetuada por meio de um trabalho educacional colaborativo, desenvolvida através de algumas práticas como: corrigir, discutir e contrapor ideias, tornando todos mediadores na busca pela apropriação do conhecimento.

\section{ASPECTOS METODOLÓGICOS}

Nesta pesquisa seguimos uma abordagem predominantemente qualitativa (Bogdan \& Biklen, 1994), pautada na metodologia de pesquisa-ação que, de acordo com Thiollent (1986), objetiva uma maior interação entre o pesquisador e o sujeito, busca promover, principalmente, a transformação social do grupo pesquisado e a solução de problemas intrínsecos às suas atividades. Ainda segundo esse autor, ao conhecer o sujeito (saber qual é sua situação, quais os problemas relacionados as suas atividades) planeja-se a 
ação (o que se tem a fazer para alterar a situação). Assim, existe uma relação entre a descrição dos fatos e as ações dirigidas ao sujeito, porém, não é apenas a descrição que determina o tipo de ação transformadora que será aplicada, deve-se levar em conta também aspectos ideológicos, políticos, jurídicos, sociais, entre outros (Thiollent, 1986).

Nesse sentido, por meio da observação participante, foi possível compreender que os membros do EES apresentaram dificuldades relacionadas ao uso de conhecimentos matemáticos necessários na cadeia produtiva deste EES, visto que essas pessoas deixaram a escola há muito tempo sem tê-la concluído. Aliado a isso, esses trabalhadores possuem transtornos mentais, o que faz com que apresentem NEE. Dessa forma, os conteúdos matemáticos podem ser um empecilho em suas atividades de trabalho. O principal problema do grupo tratado nesse trabalho tinha a ver com a dificuldades no contexto dos conhecimentos matemáticos quanto às práticas relacionadas ao cálculo referente ao troco a ser devolvido para um cliente no processo de venda.

Assim, em nossa intervenção, caminhamos no sentido de sanar as dificuldades dessas pessoas no trato com a matemática e, no caso apresentado nesse trabalho, com relação ao cálculo do troco, buscando também a emancipação do grupo enquanto um EES, isto é, buscamos contribuir com os princípios da ES.

Num primeiro momento, foi realizada a produção de dados, a fim de buscar o entendimento do problema inerente às atividades de trabalho do grupo, por meio da convivência com realidade dos sujeitos da pesquisa e do seu cotidiano de trabalho, em conversas informais e entrevistas semiestruturadas registradas em diários de campo do pesquisador. Em seguida, considerando elementos da Etnomatemática deste grupo (levantados na fase de coleta de dados) foram realizadas intervenções pedagógicas de Educação Matemática em formas de oficinas junto a este EES a fim de abordar conhecimentos matemáticos pertinentes ao cotidiano de trabalho desse grupo. Buscamos, ainda, desenvolver as capacidades de Literacia e Numeracia (Rosa e Orey, 2018), aspectos também não abordados em intervenções anteriores. Essas oficinas foram registradas em um diário de campo do pesquisador.

No diagnóstico realizado antes da etapa das oficinas pedagógicas observamos que, embora operações numéricas tivessem sido trabalhadas em intervenções anteriores, o 
grupo ainda tinha dificuldade em relação ao processo de cálculo do troco nas vendas dos produtos. Portanto, demos prioridade em sanar essa dificuldade durante as oficinas focadas neste trabalho. Tal assunto foi trabalhado em oficinas semanais de uma hora e meia de duração durante aproximadamente dois meses (de outubro a dezembro de 2017).

O EES focalizado neste trabalho possui em torno de vinte membros, no entanto, há bastante rotatividade no cotidiano de trabalho e em geral somente oito deles o frequentam com assiduidade. Todos os membros do EES foram convidados a participar, porém, apenas três deles concordaram: Diego, Felipe e Mário (nomes fictícios), com idades entre trinta e cinquenta anos. Os outros membros desse EES trabalhavam na produção do artesanato ou na reciclagem do papel, dessa forma, se parassem suas atividades, comprometeriam o trabalho do EES. Desses três participantes, os dois primeiros possuem um quadro clínico bastante estável, o que possibilita que realizem as atividades do grupo sem maiores dificuldades, já o terceiro tem um quadro de trauma advindo de um assalto em uma loja na qual trabalhava como caixa. Diego e Felipe já trabalhavam com as vendas em feiras fazendo cálculos de valor de vendas e de trocos, o que favoreceu as intervenções pedagógicas propostas. Mário estava em um processo para começar a participar das vendas do EES, porém já tinha um conhecimento sobre trabalho com compra e venda, especialmente com o cálculo de troco que adquiriu quando trabalhou como caixa.

Tomando como referencial a teoria Vygotskyana, nas oficinas pedagógicas de Educação Matemática utilizamos a concepção de trabalho colaborativo para a aprendizagem de matemática, a fim de contribuir com os pressupostos estabelecidos pela ES, em especial visando fortalecer o princípio da cooperação, como já mencionado.

Portanto, com base em pressupostos de uma Educação Inclusiva, dos princípios da Etnomatemática e da ES, propusemos aos membros deste EES oficinas pedagógicas de Educação Matemática de modo que todos tivessem a mesma importância e trabalhassem de forma conjunta, auxiliando uns aos outros.

\section{DESCRIÇÃO E ANÁLISE DOS DADOS}

Com base no diagnóstico anteriormente apresentado, para que fosse desenvolvido um trabalho colaborativo em relação ao processo de cálculo do troco nas vendas dos 
produtos, foram propostas situações-problema que simulassem o processo de venda na qual os membros do EES seriam os vendedores e o pesquisador seria o comprador. Essas simulações vão ao encontro da ideia de Numeracia, já que por meio da contextualização foram desenvolvidas situações relacionadas ao cotidiano do EES que envolveram conceitos numéricos. Além disso, tais situações também possibilitaram o desenvolvimento da capacidade de Literacia, pois as simulações tiveram como intuito facilitar a rotina diária do empreendimento no que diz respeito a capacidade de verificação dos preços, utilização de unidades monetárias e realização de operações matemáticas.

Compreendemos ainda que o recurso de simulações de uma situação real favoreceu o uso da imaginação (atuação do sujeito sobre uma situação imaginária), fator que de acordo com Vygotsky (2006), ajuda na atribuição de significado aos conteúdos envolvidos. Para auxiliar em tais situações-problema, foram utilizadas notas de dinheiro fictícias (de brinquedo), a fim de que os trabalhadores tivessem maior familiaridade com o sistema monetário brasileiro. Abaixo apresentamos alguns trechos referentes ao procedimento utilizado em uma das oficinas:

Pesquisador: Quanto custa os produtos vendidos pelo EES?

Diego: A agenda custa $R \$ 40,00$, o caderno custa $R \$ 20,00$ e o bloquinho custa $R \$$ 5,00 .

Pesquisador: Gostaria de comprar duas agendas, três cadernos e quatro bloquinhos. Nesta situação, os três participantes da oficina, com auxílio uns dos outros, fizeram o cálculo da venda. De forma dialogada buscou-se a compreensão de como os membros do EES realizaram esse cálculo e foi possível perceber que eles sabiam que era necessária uma soma para encontrar o valor total de venda. A situação trabalhada considerou os preços utilizados na feira pelo EES, no qual podemos perceber que eram valores sempre redondos, ou seja, sem utilização dos centavos, fato utilizado para que facilitasse o processo dos cálculos durante a feira.

Percebermos nessa ação uma prática Etnomatemática, isto é, um conhecimento matemático do grupo utilizado em seu cotidiano, que foi preservado durante a oficina realizada. De acordo com Knijnik e outros. (2012), uma abordagem Etnomatemática entende a matemática como uma disciplina diretamente implicada na produção de subjetividades dos sujeitos, que dão valor as suas vivências, experiências e 
conhecimentos do mundo. É importante para as oficinas que sejam consideradas as particularidades do sujeito envolvido no processo de ensino-aprendizagem.

Ademais, também se observou que os três participantes souberam fazer a soma, visto que ela havia sido trabalhada em intervenções pedagógicas anteriores. Em alguns momentos, um ou outro se confundiu na realização do cálculo, feito com lápis e papel, o que tornou importante que as ideias fossem contrapostas e que se discutisse o porquê daquele resultado. Buscamos sempre que eles tentassem ajudar-se mutuamente e pudessem chegar a um consenso, conseguindo explicar como havia sido feito o cálculo e porque achavam que era aquele o resultado.

Considerando que essa prática poderia ser utilizada na feira e tendo em vista que alguns possuíam mais facilidade do que outros quanto à utilização da matemática, tal trabalho colaborativo favoreceu a prática de venda, desenvolvida sem erros e coletivamente.

Posteriormente, nessa simulação, chegou-se a um consenso quanto ao valor de venda, e foi proposta então uma nova situação-problema relacionando o valor do troco da simulação focada anteriormente:

Diego: $O$ valor total de compra é $R \$ 160,00$.

Pesquisador: Se eu pagar com quatro notas de $R \$ 50,00$. Qual o valor do troco?

Os membros do EES inicialmente discutiram qual foi o valor total dado para pagar a compra e então calcularam o troco. A identificação do valor dado para pagamento foi algo simples, pois tratava-se de uma soma, que havia sido trabalhada na parte anterior da simulação.

No entanto, a situação do troco gerava algumas complicações, já que envolvia o conceito de subtração. Os membros do EES compreenderam o procedimento a ser realizado, o qual chamaram de "conta de menos", porém tinham dificuldades em fazêlo. Foi constatado que na feira eles utilizavam a calculadora, mas nem sempre sabiam se o cálculo havia sido feito de forma correta. Com isso, essa etapa da comercialização era um obstáculo importante a ser resolvido pelo grupo.

Assim, para finalizar a simulação, trabalhamos o procedimento da subtração por meio de algoritmo escrito e da troca no sistema posicional na realização desta operação. Além disso, foi trabalhado e proposto o uso da calculadora como uma prática a ser utilizada na feira com o intuito de que os membros pudessem verificar o resultado a que chegaram para a devolução do troco, como apresentado no trecho abaixo: 
Geromel Meneghetti, R.C. \& Oliveira Filho, E. (2019). Etnomatemática e Trabalho Colaborativo na Educação Inclusiva de Adultos no Contexto da Economia Solidária. Revista Latinoamericana de Etnomatemática,12(4), 103-122. DOI: 10.22267/relatem.19124.38

Pesquisador: Como o troco é calculado a partir da seguinte operação:

Troco $=$ Valor dado pelo cliente - Valor total da venda.

Pesquisador: $O$ que podemos fazer para conferir se o troco foi calculado corretamente?

Após discussão coletiva chegou-se à relação:

$$
\text { Troco }+ \text { Valor total da venda }=\text { Valor dado pelo cliente }
$$

Felipe fez o cálculo mental de forma rápida, enquanto Diego resolveu utilizando a calculadora para verificar.

Felipe: $O$ valor da venda dá 80 reais de agenda, 60 de caderno e 20 de bloquinho, então dá, 180.

Diego: Não, olha! Dá 160.

Mário: Isso, 160.

Diego mostrou os cálculos para os demais, Felipe tentou compreender, e na sequência perguntou ao pesquisador. Mário apenas concordava com os outros.

Felipe: Então, se deu quatro notas de 50, pagou 200 reais né? Então o troco é 40?

Pesquisador: Isso, foi pago 200 reais. Todos concordam que o troco é 40 ?

Diego: Isso Olha! 200 - $160=40$. E se fizer o valor do troco, 40, mais o valor da venda, 160, dá 200, que é o valor pago.

Desta forma, a cada situação-problema, os membros do EES calculavam tal relação a fim de verificar se o troco estava correto, contribuindo com a segurança dos trabalhadores em relação aos cálculos realizados. Além disso, o pesquisador incentivou atitudes para favorecer a relação de trabalho para que, de forma coletiva, os membros chegassem sempre a um acordo sobre o valor do troco a ser dado, como colocado por Vygotsky (1991).

Entendemos que assim, em situações futuras similares eles poderão realizar cálculos do valor das vendas e do valor dos trocos, enquanto outros poderão atuar na verificação, estimulando a contribuição de todos nesse processo. Essa possibilidade de conferir os resultados a que chegavam mostrou-se importante para a autonomia dos membros deste EES, uma vez que passaram a ter maior segurança na realização do cálculo e, com isso, conseguiriam efetuá-los sem ajuda de terceiros. 
Vale ainda destacar que o trabalho realizado coletivamente favoreceu também a cooperação na execução das tarefas. Isso pode ser percebido melhor numa fala de Diego.

Diego: É... vai facilitando para a gente tomar cuidado né, para não ser roubado, para tomar cuidado com roubo, com... com... a gente tem mais autonomia! Eu acho assim, a gente tem mais responsabilidade com as coisas!

Assim, no entendimento de Diego, as oficinas contribuíram para além do espaço de trabalho, uma vez que ele relatou que usava o conhecimento adquirido em tais oficinas para calcular o troco de produtos que comprava em seu cotidiano, a fim de que, como ele mesmo acrescentou, tivesse mais autonomia e responsabilidade. Durante o desenvolvimento das oficinas, percebemos também que quando um membro do EES possuía uma dúvida os outros lhe explicavam a fim de saná-la, ou seja, um auxiliava o outro na resolução. Desta forma, verificamos que o trabalho colaborativo fez com que aqueles que possuíam maior facilidade auxiliassem aqueles que tinham mais dificuldades.

\section{CONSIDERAÇÕES FINAIS}

Retomando nossa questão de pesquisa: Como a Educação Matemática pode ser abordada no contexto da Educação Inclusiva de Adultos e da Economia Solidária visando sanar algumas dificuldades de trabalho de pessoas com Necessidades Educacionais Especiais e contribuir com os princípios deste tipo de economia? É possível apontar que uma das formas de se fazer isso, é através de um trabalho pedagógico em educação matemática em que se considere os princípios da Etnomatemática e da teoria de trabalho colaborativo de Vygotsky (1991).

Nesta direção as situações-problema trabalhadas, envolvendo conhecimentos matemáticos foram elaboradas com base nas dificuldades advindas do trabalho dos membros deste EES, ou seja, da Etnomatemática do grupo, auxiliando na aprendizagem dessas pessoas. Segundo Rosa e Orey (2006) para se desenvolver uma prática Etnomatemática voltada para a ação pedagógica não deve preocupar-se somente com a vertente antropológica e etnográfica da descrição de diferentes pensamentos matemáticos desta. Faz-se importante também assumir uma perspectiva voltada para os aspectos políticos e pedagógicos. Nesse sentido, foram desenvolvidas neste trabalho as 
capacidades de Numeracia e Literacia, visto que foram trabalhados conceitos numéricos a partir da contextualização de situações de trabalho do EES, ademais tais situações tinham como intuito auxiliar nas tarefas diárias do grupo por meio do aprendizado e emprego das operações básicas.

Também foram compreendidos e respeitados os procedimentos matemáticos que o grupo utilizava, sem apresentar métodos matemáticos muito distantes desses, a fim de valorizar as práticas matemáticas próprias do grupo. Nesse sentido Knijnik e outros. (2012) afirmam que trabalhos educativos em matemática que focalizam a realidade do aluno/aprendiz, podem tanto contribuir com a legitimação da matemática própria de um determinado grupo cultural, quanto dar sentido a matemática escolar.

Para Knijink (2001), educadoras e educadores matemáticos devem levar em consideração e estarem atentos a questão da inclusão no ensino de matemática, isso pode ocorrer por meio de um trabalho docente em que considere as particularidades do educando/aprendiz. Fato que poderá contribuir na construção de um mundo socialmente mais justo. Também segundo Lübeck e Rodrigues (2013), a Educação Matemática Inclusiva pode ser feita por meio da Etnomatemática, a qual busca valorizar os saberes de grupos que não são dominantes na sociedade. Nesse sentido, por exemplo, no caso de um EES, esses saberes dizem respeito às diferenças, a solidariedade e a cooperação entre educador e aprendiz.

Nesse contexto, acreditamos que por meio das intervenções pedagógicas de ensino de matemática pudemos auxiliar para que este grupo, por meio das suas diferenças, das suas exclusões pelo contexto da baixa escolaridade, do transtorno mental e do desemprego, se tornasse mais autônomo no desenvolvimento das atividades de seu cotidiano de trabalho e ainda, pudesse desenvolver a cooperação nos afazeres que envolvessem matemática, e também nos demais afazeres do EES em questão. Assim a superação das dificuldades e a aquisição de uma segurança maior na utilização de conhecimentos matemáticos mostraram-se essenciais para maior fluidez no desenvolvimento das atividades cotidianas de trabalho. Entendemos que este fato contribuiu de forma significativa para a emancipação dos membros do EES, que se deu através da transformação da relação desses com a matemática.

A emancipação, quanto ao aprendizado do conteúdo matemático relacionado ao troco pôde ser percebida quando Diego, a partir das intervenções realizadas, relatou que as 
mesmas além de facilitar seu trabalho no cotidiano do EES(que é um aspecto esperado da pesquisa-ação), também o auxiliou em processos fora deste cotidiano, ou seja, também existiu uma transposição do conhecimento adquirido para outras esferas do seu dia-a-dia. Portanto, percebemos que este membro do EES pôde ter mais autonomia nos seus afazeres diários a partir da compreensão de conhecimentos matemáticos advindos da oficina da qual participou.

Nas oficinas foram utilizadas ainda as concepções de Vygotsky (1991) sobre trabalho colaborativo, a fim de que os membros do EES desenvolvessem esse método de trabalho. A abordagem foi benéfica, pois auxiliou no que diz respeito às discussões sobre os procedimentos e conceitos matemáticos. A participação de todos favoreceu o desenvolvimento da comunicação e do relacionamento entre os membros deste EES, contribuindo tanto para o ensino e quanto para a aprendizagem dessas pessoas, além do fortalecimento do princípio da cooperação, que é um dos pilares da ES.

A ES surge para essas pessoas como forma de geração de renda e inserção social. Acreditamos que atuação em Educação Matemática tal como a focalizada neste trabalho pôde contribuir no fortalecimento do empreendimento, visto que seus membros se tornaram mais seguros no processo de vendas na feira, onde conseguem uma forma de renda e inserção na sociedade de maneira justa.

\section{AGRADECIMENTOS}

À Pró-reitoria de Graduação da USP (Universidade de São Paulo) (Programa Ensinar com Pesquisa e Programa Unificado de Bolsas para Graduação).

\section{REFERÊNCIAS}

Adams, T., \& Santos, A. M. D. (2013). Economia Solidária: um espaço peculiar de educação popular. In: STRECK, D. R., \& ESTEBAN, M.T., Educação Popular: lugar de construção social coletiva. (pp. 260 - 273). Rio de Janeiro: Editora Vozes.

Bogdan, R C., \& Biklen, S K. (1994). Investigação qualitativa em educação: uma introdução à teoria e métodos. Porto: Porto Editora.

Brasil. Ministério do Trabalho e Emprego. Secretaria Nacional de Economia Solidária. (2006). Atlas de Economia Solidária no Brasil. Brasília: MTE/SNES.

Brasil. Organização Pan Americana da Saúde. (2018). Folha informativa - Transtornos mentais.

Recuperado

de: 
<https://www.paho.org/bra/index.php?option=com_content\&view=article\& id=5652:folha-informativa-transtornos-mentais\&Itemid=839 >.

Brasil. Ministério da Saúde. (2019). Saúde mental: o que é doenças, tratamentos e direitos. Recuperado de: <http://portalms.saude.gov.br/saude-para-voce/saude mental/acoes-eprogramas-saude-mental/centro-de-atencao-psicossocial-caps $>$.

Costa, D. A. F. (2006). Superando limites: a contribuição de Vygotsky para a educação especial. Revista Psicopedagogia, 23(72), 232-240.

Damiani, M. F. (2008). Entendendo o trabalho colaborativo em educação e revelando seus benefícios. Educar em revista. (31), 213-230.

D’Ambrosio, U. (1996) Educação Matemática: Da Teoria à Prática. Campinas. Papirus.

D’Ambrosio, U. (2001) Etnomatemática: Elo entre as tradições e a modernidade. Minas Gerais. Autêntica.

D’Ambrosio, U. (2008). O Programa Etnomatemática: uma síntese. Acta Scientiae. 10 (1), 07-16.

D’Ambrosio, U. (2018) Etnomatemática, justiça social e sustentabilidade. Estudos Avançados. 32 (94), 189-204.

Knijnik, G. (2001). Educação matemática, exclusão social e política do conhecimento. BolemaBoletim de Educação Matemática. 14 (16), 12-28.

Knijnik, G; Wanderer, F; Gionco, I. M \& Durate, C. (2012). Etnomatemática em movimento. Autêntica.

Kruppa, S. M. P. (2005). Uma outra economia pode acontecer na educação: para além da Teoria do Capital Humano. In: KRUPPA, S. M. P. (org). Economia solidária e educação de jovens e adultos. Brasília: Instituto Nacional de Estudos e Pesquisas Educacionais Anísio Teixeira (INEP).

Lübeck, M. \& Rodrigues, T. D. (2013). Incluir é Melhor que Integrar: uma concepção da Educação Etnomatemática e da Educação Inclusiva. Revista Latinoamericana de Etnomatemática, 6(2), 8-23.

Meneghetti, R. C. G. (2013). Educação matemática e economia solidária: uma aproximação por meio da etnomatemática. Revista Latinoamericana de Etnomatemática. 6 (1), 4066.

Meneghetti, R. C. G. \& Cunha, R. S. M. T. (2016). Economia solidária: histórico, conceitos e relações com a educação matemática. In: Meneghetti, R. G. M. (Org.). A educação matemática no contexto da economia solidária. (1a ed., pp.23-32). Curitiba. Appris.

Meneghetti, R. C. G. \& Gargarella, B. C. (2019). Solidarity economy and inclusive mathematical education for adults with special needs. In: Kollosche, D.; Marcone, R; Kinnige, M; Penteado, M.G; Skovsmose, O. (Eds.). Inclusiv Mathematics Education: State of the art Researsh from Brazil and Germany. Suiça: Springer Nature AG. (pp. 499-514).

Pinho, K L. R. \& Machado, M L. T. (2015). Economia Solidária e a produção de cidadania na saúde mental: um estudo dos dispositivos de inclusão social pelo trabalho no estado de São Paulo. In: Souza, A. R; Zanin; M. (Org.). A Economia solidária e os desafios globais do trabalho, São Carlos. Edufscar. 
Singer, P. (2002). Introdução à economia solidária. Fundação Perseu Abramo.

Singer, P \& Souza, A. R. A. (2000). Economia Solidária do Brasil - A autogestão como resposta ao desemprego. São Paulo. Contexto.

Rosa, M. \& Orey, D. C. (2006). Abordagens atuais do programa etnomatemática: delineando um caminho para a ação pedagógica. Bolema. Rio Claro. 19 (26), 19- 48.

Rosa, M \& Orey, D. C. (2018). Propondo um Currículo Trivium Fundamentado nas Perspectivas da Etnomatemática e da Modelagem. Revista Educação Matemática em Foco. 7 (2), 63-98.

Thiollent, M. (1986). Metodologia da pesquisa-ação. São Paulo. Cortez. Autores Associados.

Vygotsky. L. S. (2006). La, imaginacion y el arte en la infância. (7 ed). Madrid. Akal.

Vygotsky, L. S. (1991). A formação social da mente. (J. Cipolla Neto \& L. S. M. Barreto; S. C., trad). (4 ed). São Paulo. Livraria Martins Fontes Editora Ltda. 